\title{
Future perspective of new tooth creation
}

\author{
Mouetaz Kheirallah* \\ Maxillofacial Surgery Department, College of Dentistry, Alanadalos University for Medical Sciences, Al-Qadmous, Syria
}

(Received Aug 22, 2017; Revised version received Sep 5, 2017; Accepted Sep 6, 2017)

\begin{abstract}
Currently, outcomes of dental stem cells studies indicate that the tooth is an available source for clinical application. Finding a universal cell that can morph into many several types of oral tissues is a key for new tooth creation. If dental stem cells are isolated to form new tooth buds, with creation of an imitative condition to the embryonic jaw, this will be a revolutionary new way to replace a missing tooth. Although investigators have created tooth-like structures in studies, so far, later dental stem cells investigations will be able to create a workable vascularized implant in the human body. This review study discusses current challenges in creating a biological environment that mimics the condition of teeth as they form in an embryo.
\end{abstract}

KEY WORDS: Dental stem cells, Tooth creation, Tooth development, Tooth-like structures

\section{Introduction}

The therapeutic philosophy is the crucial factor that determines tooth prognosis [1]. Missing tooth require solving a problem in the form of implants or dentures. Effective, workable implant with blood vessels in the jaw might be the best choice than synthetic implants. Consequently, there is a clinical desire to regenerate tooth root with periodontal ligament. Tooth development is a common interactional labour among ectodermal oral epithelial cells, and neural crest-derived mesenchymal cells [2]. The dentin, cementum and dental pulp originate from neural crest-derived mesenchyme whereas tooth enamel derives from oral epithelium [3]. Stem cells from adult tooth pulp can be isolated and converted into teeth buds; then the tiny tissue clusters may finally grow into a natural tooth. For that reason, exploitation of dental stem cells has preponderance above available tooth replacement therapies. It is renowned that embryonic stem cells are giving rise to any

\footnotetext{
*Corresponding author: Mouetaz Kheirallah

Maxillofacial Surgery Department, College of Dentistry, Alanadalos University for Medical Sciences, Al-Qadmous, Syrian Arab Republic. Temporarily a visitor at College of Dental Medicine, Majma'ah University, KSA Tel.: +963-43-657600, Fax: +963-43-656174

E-mail: moutazkheirallah@gmail.com,mk@au.edu.sy,

m.kheirallah@mu.edu.sa
}

cell type (totipotent) while adult stem cells could differentiate into a limited amount of cell patterns. Furthermore, embryonic stem cells might have the capacity to distinguished for any cell type that arises from ectoderm, endoderm and mesoderm. Finding universal cell that can morph into many several types of oral tissue is a key for growing a new tooth. The current understanding of tooth development and eruption is undoubtedly a series of actions, not possible to separate. The presence of dental follicle is required for tooth eruption and becomes apparent that it regulate the osteogenesis and osteoclastogenesis needed for tooth eruption [4,5]. If the dental stem cells are isolated to form new tooth buds, with the creation of an imitative condition to the embryonic jaw, where tooth begin to take shape, this will be a revolutionary new way to replace the missing tooth. Although investigators have lucky to create tooth like structures in brute studies, so far, later dental stem cells investigations will be able to create a workable vascularized implant in a human body. This review article will discuss the current challenges to create a biological environment that mimics the condition of teeth as they form in an embryo.

\section{Human tooth development}

Usually, tooth growth could be divided into three stages, pre-eruptive stage, eruptive stage and post-eruptive stage. 
During the pre-eruptive stage, the enamel grows from ectoderm of the oral cavity, whereas all other tissues come from the connected mesenchyme [6]. Tooth buds originate from growing the dental laminae into the mesenchyme. The dental papilla (mesenchyme) folded back on itself inside the deep surface of each ectodermal bud to form the dentin and dental pulp [7]. The ectoderm above the papilla forms the enamel organ which contains external cellular stratum and internal enamel epithelium. The zone among these two strata constitutes the bulk of the cap (enamel reticulum) [8]. The periodontal ligament and the cementum are formed by the surrounding mesenchyme, after the figuration of the dental papilla and enamel organ. The mesenchymal cells of dental papilla closed to the internal enamel epithelium, produce pre-dentin by differentiation into odontoblasts. When the dentin deposit, the odontoblasts regress toward the centre of the dental papilla and odontoblastic processes, remain in the dentin (dentinal fibers) [8]. Cells of the internal enamel epithelium close to the dentin shape ameloblasts to produce the enamel above the dentin stratum. The inner and external enamel epithelia connect to grow into the mesenchyme to start the root formation. Dentin growth leads to smaller pulp cavity which begins to be a narrow canal for the nerves and vessels. Cementoblasts from the internal cells of the dental sac produce the cementum. The outer cells of the dental sac begin to be active after the bone and the periodontal ligament formation [6]. Accordingly, the tooth gathered.

\section{Provenance of dental stem cells}

Postnatal autologous tooth germ cells (third molars) or autologous dental stem cells are of limit obtainable, for that reason, it's hard to be applied clinically. However, adult stem cells show multipotency and self-renewal capacity and have separated from various parts of the tooth. These sources are dental follicle, apical root papilla, periodontal ligament and exfoliated primary teeth. Otherwise, bone marrow stromal cells can differentiate into enamel and dentin structures [9]. Moreover, to produce tooth tissues, researchers have used combined suspension of single cell embryonic tooth germ with scaffold through regulation of certain signalling pathways, they found that individual cells can reorganise themselves and differentiate into odontoblasts and ameloblasts. However, the limit of embryonic germ confined these methods for clinical application [10].

From dental follicle (DFSCs)

During tooth development, the dental papilla and the enamel organ ringed by ectomesenchyme tissue which is called dental follicle [11]. It is believed that it may be the progenitor of other cells of the periodontium, including osteoblasts and cementoblasts [12]. DFSCs differentiate into periodontal ligament fibroblasts which excrete the collagen to react with the fibres on the surface of closed cementum and bone. When DFSCs were transplanted into severe combined immunodeficiency mice, they formed cementoblast-like cells [13]. However, other reports indicated little cementum or bone formation when human adult stem cells used for periodontal regeneration [14]. Moreover, there have been several studies subscribe the angiogenic, and neurotrophic effects of DFSCs. All these studies confirmed the neurogenic potential of DFSCs because they originate from the embryonic neural crest [15]. Kanao et al. [16] have investigated the capacity of human DFSCs to differentiate into neural cells, they concluded that DFSCs were undergoing neuronal differentiation via neurospheres, while expression of nestin and $\beta$-IIItubulin was downregulated. Also, Heng et al. [17] have inspected whether culture can enhance neural differentiation of DFSCs on decellularised matrix substrata derived from neurogenesis of human embryonic stem cells. This study concluded that decellularised matrix substrata derived from neurogenesis of embryonic stem cells could enhance the neurogenic potential of DFSCs.

\section{From apical papilla (SCAP) or dental pulp (DPSCS)}

Extracted third molars in dental practice are a reliable source to obtain active stem cells with embryonic-like properties. During root growth, before root eruption, the root apical papilla is presented, and the dental pulp is a useful source of dental pulp stem cells [18]. DPSCs showed elevated frequency of colony formation and propagation. Furthermore, embedded DPSCs were differentiated into active neurons [19], and SCAPs have the capability to differentiate into odontoblasts and other mesenchymal cells such as adipocytes, chondrocytes and osteoblasts [20-22]. Transplantation of these cells into an impaired immune system of mice demonstrated their efficiency to create dentin and pulp structures [23]. Sonoyama et al. [24] have transplanted both human SCAP and PDLSCs to generate a root/periodontal complex capable of supporting a porcelain crown, resulting in normal tooth function. Although, demonstrated results, more investigations are needed on the properties of these cells. The author with coworkers, in another study, have discovered SCAP which showed a different population of stem cells than DPSCs. They applied 
SCAP to engineer bio-roots using minipigs, and they concluded that these cells are a promising cell source to regenerate bio-roots for future clinical applications [25]. The evidence is collecting to support the assumption that SCAP appears the origin of essential odontoblasts for root dentin formation, whereas DPSCs are likely the source of replacement odontoblasts [18].

From human periodontal ligament (PDLSCs)

Impacted third molars are a reliable source to obtain PDLSCs that are multipotent postnatal stem cells [26], possess characteristics of mesenchymal stem cells, but there is incomparability among different studies for their culture and consistency. It notified that periodontal tissues originate from migrated neural crest cells during tooth development [27], whatever, PDLSCs obtained from ripe periodontal ligaments instead of the neural crest, showed stem cell properties such as the mesenchymal stem cells [28]. Several studies have reported a population of stem cells from human periodontal ligaments capable of differentiating into cementoblasts and connective tissue rich in collagen I in vitro and in vivo [26,29]. Furthermore, periodontal ligaments are under forces of mastication; therefore, they may have an internal origin to enable periodontal ligament cells number, for that reason, may they be preferable than dental stem cells isolated during the formulation of periodontal ligament structures [30]. Several studies have reported that stem cells transplantation has a propensity to form tumours. Amariglio et al. [31] reported that transplantation of human foetal neural stem cells might lead to multifocal brain tumour if the transplanted cells were from two donors at least. Although there is no evidence that transplantation of mesenchymal stem cells may lead to tumours, there is riskiness, wherefore this aspect should be inspected before PDLSCs transplantation. Furthermore, the study provided by Xie and Tang [32] concluded that undifferentiated PDLSCs triggered several immune responses with high lymphocytic infiltration and elevated IFN- $\gamma$ secretion, they suggested that in vitro differentiation may alter stem cell immune properties. Regardless of the fact that PDLSCs suppressed the immune response before and after osteogenic induction before transplantation the immune properties of PDLSCs should be investigated [33].

\section{From human exfoliated deciduous teeth (SHED)}

Human exfoliated deciduous teeth could be a useful source to isolate several types of stem cells such as osteoblast, odontoblast, adipocytes, chondrocytes and neural cells [34]. The primary task of these cells is the formulation of hard tissues and could be applied to increase bone regeneration $[35,36]$. Stem cells from human exfoliated deciduous teeth can differentiate into osteoblasts but cannot regenerate entire dentinal and pulpal structures in vivo [37]. Furthermore, it secretes neurotrophic factor to regenerate the motor neurons after dental trauma, and so on, SHED can be applied for neurodegenerative diseases treatment. The principal advantage of these cells is that the immunosuppressive therapy is not required when autologous transplantation is used [38]. Consequently, exfoliated teeth may be an excellent unique resource for stem cells therapy including autologous stem cells transplantation and tissue engineering [34].

Odontogenic reacting epithelial cells

Many biological factors have been used to enable interactions between epithelial and mesenchymal stem cells [39], for example fibroblast growth factor and bone morphogenetic protein combined with these cells may induce them [40]. The oral epithelium of murine embryos showed creation of tooth formation in non-dental mesenchyme [41]. Furthermore, epithelial cells from mouse embryos have been showed to result in the tooth like frameworks if joined with embryonic dental mesenchyme, however, not whole functional teeth [42-44]. Yajima-Himuro et al. [45] have transplanted bioengineered tooth germ into the alveolar bone with an epithelial component, and concluded that epithelium from the bioengineered tooth fused with the oral epithelium, and the junctional epithelium was apparently formed around the bioengineered tooth 50 days after transplantation.

\section{From nondental origin}

Studies reported that odontogenic epithelial signals could stimulate non-dental mesenchymal cells. The combination of inductive embryonic oral epithelium with bone marrow-derived cells or neural stem cells can form tooth structures in vitro [46]. Ikeda et al. [47] have demonstrated that transplantation of embryonic tooth primordia into alveolar bone in the lost tooth alveolus for sufficient time could grow to form whole tooth. Furthermore, when tooth germs are separated and admitted reconnecting in a scaffold, they re-aggregate to reform the tooth germs [48]. The advent of pluripotent stem cells should speed up the application of regenerative tissues or organ such as the tooth in the clinic [49]. Researchers have used the human urine to obtain pluripotent stem cells and to create tooth structures in mice with a success rate of up to $30 \%$ [50]. 
They have concluded that these cells are capable of tooth creation using odontogenic signals from embryonic dental mesenchyme and pre-differentiating them into epithelial sheets [50]. Furthermore, the created teeth had comparable properties to regular human teeth excluding the hardness; they also resulted that these cells do not form tumours when transplanted into the body conversely other stem cells [50]. Anyway, many defiances still need to be overcome, and more knowledge is required before to become a routine clinical approach to the treatment of diseases [51].

\section{Conclusion}

Currently, outcomes of dental stem cells studies indicate that tooth is a useable source for clinical application of adult mesenchymal stem cells. Although investigators have successes to generate tooth like structures, they cannot replace actual teeth, and there remain several determinations, such as limitation to animal models. However, their clinical applications still to investigate. Functional human tooth creation may need many months or even many years, while production of mouse tooth may take a few weeks only. Investigations on blood and nerve supply in human teeth are required to move forward the dental regenerative therapy. Furthermore, there are other barriers in identification, isolation, cleaning and growing stem cells consistently in labs. Many problems and risks still need to be resolved. Up to date, it is premature to consider stem cells as an efficient procedure for tooth replacement.

\section{Conflict of Interest}

The authors declare that they have no competing interests.

\section{ORCID}

Mouetaz Kheirallah 0000-0002-3094-3195

\section{References}

1. Chang HY, Yun WH, Hyun HN, Pi SH, You HK. Clini- cal and radiographic analysis of the causes of tooth extraction. Oral Biol Res 2015;39:24-32.

2. Cordero DR, Brugmann S, Chu Y, Bajpai R, Jame M, Helms JA. Cranial neural crest cells on the move: their roles in craniofacial development. Am J Med Genet A 2011;155A:270-279. doi: 10.1002/ajmg.a.33702.

3. Thesleff I. The genetic basis of tooth development and dental defects. Am J Med Genet A 2006;140:2530-2535. doi: 10.1002/ajmg.a.31360.

4. Wise GE, Yao S, Odgren PR, Pan F. CFS-1 regulation of osteoclastogenesis of tooth eruption. J Dent Res 2005; 84:837-841. doi: 10.1177/154405910508400911.

5. Marks SC, Schroeder HE. Tooth eruption theories and facts. Anat Rec 1996;245:374-393. doi: 10.1002/(SICI) 1097-0185(199606)245:2<374::AID-AR18>3.0.CO;2-M.

6. Bath-Balogh M, Fehrenbach MJ. Illustrated Dental Embryology, Histology, and Anatomy. 3rd ed. Elsevier; 2011.

7. Gartner LP. Essentials of Oral Histology and Embryology. 3rd ed. Jen House Publishing Company Baltimore MD; 1999.

8. Ross MH, Gordon IK, Wojciech P. Histology: a text and atlas with cell and molecular biology. 4th ed. Philadelphia, Pa.: Lippincott Williams \& Wilkins; 2002.

9. Li ZY, Chen L, Liu L, Lin YF, Li SW, Tian WD. Odontogenic potential of bone marrow mesenchymal stem cells. J Oral Maxillofac Surg 2007;65:494-500. doi: 10.1016/j.joms.2006.09.018.

10. Young CS, Terada S, Vacanti JP, Honda M, Bartlett JD, Yelick PC. Tissue engineering of complex tooth structures on biodegradable polymer scaffolds. J Dent Res 2002;81:695-700.

11. Ten Cate AR. Oral Histology: Development, Structure, and Function. 5th ed. St. Louis: Mosby; 1998.

12. Yao S, Pan F, Prpic V, Wise GE. Differentiation of stem cells in the dental follicle. J Dent Res 2008;87:767-771. doi: 10.1177/154405910808700801.

13. Handa K, Saito M, Tsunoda A, Yamauchi M, Hattori S, Sato S, Toyoda M, Teranaka T, Narayanan AS. Progenitor cells from dental follicle are able to form cementum matrix in vivo. Connect Tissue Res 2002;43:406-408.

14. Lin NH, Gronthos S, Bartold PM. Stem cells and periodontal regeneration. Aust Dent J 2008;53:108-121. doi: 10.1111/j.1834-7819.2008.00019.x.

15. Ratajczak J, Bronckaers A, Dillen Y, Gervois P, Vangansewinkel T, Driesen RB, Wolfs E, Lambrichts I, Hilkens P. The Neurovascular Properties of Dental Stem Cells and Their Importance in Dental Tissue Engineering. Stem Cells Int 2016;2016:9762871. doi: 10.1155/2016/ 9762871.

16. Kanao S, Ogura N, Takahashi K, Ito K, Suemitsu M, Kuyama K, Kondoh T. Capacity of Human Dental Follicle Cells to Differentiate into Neural Cells In Vitro. Stem 
Cells Int 2017;2017:8371326. doi: 10.1155/2017/8371326.

17. Heng BC, Gong T, Wang S, Lim LW, Wu W, Zhang C. Decellularized Matrix Derived from Neural Differentiation of Embryonic Stem Cells Enhances the Neurogenic Potential of Dental Follicle Stem Cells. J Endod 2017; 43:409-416. doi: 10.1016/j.joen.2016.10.033.

18. Huang GTJ, Sonoyama W, Liu Y, Liu H, Wang S, Shi S. The Hidden Treasure in Apical Papilla: The Potential Role in Pulp/Dentin Regeneration and BioRoot Engineering. J Endod 2008;34:645-651. doi: 10.1016/j.joen. 2008.03.001.

19. Arthur A, Rychkov G, Shi S, Koblar SA, Gronthos S. Adult human dental pulp stem cells differentiate toward functionally active neurons under appropriate environmental cues. Stem Cells 2008;26:1787-1795. doi: 10.1634/ stemcells.2007-0979.

20. Gronthos S, Mankani M, Brahim J, Robey PG, Shi S. Postnatal human dental pulp stem cells (DPSCs) in vitro and in vivo. Proc Natl Acad Sci USA 2000;97:1362513630. doi: 10.1073/pnas.240309797.

21. Koyama N, Okubo Y, Nakao K, Bessho K. Evaluation of pluripotency in human dental pulp cells. J Oral Maxillofac Surg 2009;67:501-506. doi: 10.1016/j.joms.2008. 09.011 .

22. Graziano A, d'Aquino R, Laino G, Papaccio G. Dental pulp stem cells: a promising tool for bone regeneration. Stem Cell Rev 2008;4:21-26. doi: 10.1007/s12015-0089013-5. Erratum in: Stem Cell Rev 2008;4:65.

23. Gronthos S, Brahim J, Li W, Fisher LW, Cherman N, Boyde A, DenBesten P, Robey PG, Shi S. Stem cell properties of human dental pulp stem cells. J Dent Res 2002;81:531-535. doi: 10.1177/154405910208100806.

24. Sonoyama W, Liu Y, Fang D, Yamaza T, Seo BM, Zhang C, Liu H, Gronthos S, Wang CY, Wang S, Shi S. Mesenchymal stem cell-mediated functional tooth regeneration in swine. PLoS One 2006;1:e79. doi: 10.1371/journal.pone.0000079.

25. Sonoyama W, Liu Y, Yamaza T, Tuan RS, Wang S, Shi S, Huang GT. Characterization of the apical papilla and its residing stem cells from human immature permanent teeth: a pilot study. J Endod 2008;34:166-171. doi: 10.1016/j.joen.2007.11.021.

26. Seo BM, Miura M, Gronthos S, Bartold PM, Batouli S, Brahim J, Young M, Robey PG, Wang CY, Shi S. Investigation of multipotent postnatal stem cells from human periodontal ligament. Lancet 2004;364:149-155. doi: 10.1016/S0140-6736(04)16627-0.

27. Zhu W, Liang M. Periodontal ligament stem cells: current status, concerns, and future prospects. Stem Cells Int 2015;2015:972313. doi: 10.1155/2015/972313.

28. Kaku M, Komatsu Y, Mochida Y, Yamauchi M, Mishina Y, Ko CC. Identification and characterization of neural crest-derived cells in adult periodontal ligament of mice.
Arch Oral Biol 2012;57:1668-1675. doi: 10.1016/ j.archoralbio.2012.04.022.

29. Gault P, Black A, Romette JL, Fuente F, Schroeder K, Thillou F, Brune T, Berdal A, Wurtz T. Tissue-engineered ligament: implant constructs for tooth replacement. J Clin Periodontol 2010;37:750-758. doi: 10.1111/ j.1600-051X.2010.01588.x. Erratum in: J Clin Periodontol 2010;37:873.

30. Shi S, Bartold PM, Miura M, Seo BM, Robey PG, Gronthos $\mathrm{S}$. The efficacy of mesenchymal stem cells to regenerate and repair dental structures. Orthod Craniofac Res 2005;8:191-199. doi: 10.1111/j.1601-6343.2005.00331.x.

31. Amariglio N, Hirshberg A, Scheithauer BW, Cohen Y, Loewenthal R, Trakhtenbrot L, Paz N, Koren-Michowitz M, Waldman D, Leider-Trejo L, Toren A, Constantini S, Rechavi G. Donor-derived brain tumor following neural stem cell transplantation in an ataxia telangiectasia patient. PLoS Med 2009;6:e1000029. doi: 10.1371/journal.pmed.1000029.

32. Xie N, Tang B. The Application of Human iPSCs in Neurological Diseases: From Bench to Bedside. Stem Cells Int 2016;2016:6484713. doi: 10.1155/2016/6484713.

33. Wada N, Menicanin D, Shi S, Bartold PM, Gronthos S. Immunomodulatory properties of human periodontal ligament stem cells. J Cell Physiol 2009;219:667-676. doi: $10.1002 /$ jcp. 21710.

34. Miura M, Gronthos S, Zhao M, Lu B, Fisher LW, Robey PG Shi S. SHED: stem cells from human exfoliated deciduous teeth. Proc Natl Acad Sci USA 2003;100:5807-5812. doi: 10.1073/pnas.0937635100.

35. Pathak SD, Gite S, Bansode P, Khedgikar S, Wavdhane M. Teeth - A New Source of Stem Cells "Stem Cell Revolution Lurks in Your Mouth". IOSR Journal of Dental and Medical Sciences 2016;15:17-23. doi: 10.9790/ 0853-15111723.

36. Cordeiro MM, Dong Z, Kaneko T, Zhang Z, Miyazawa M, Shi S, Smith AJ, Nör JE. Dental pulp tissue engineering with stem cells from exfoliated deciduous teeth. J Endod 2008;34:962-969. doi: 10.1016/j.joen.2008.04.009.

37. Potdar PD, Jethmalani YD. Human dental pulp stem cells: Applications in future regenerative medicine. World J Stem Cells 2015;7:839-851. doi: 10.4252/wjsc.v7.i5.839.

38. Bansal R, Jain A. Current overview on dental stem cells applications in regenerative dentistry. J Nat Sci Biol Med 2015;6:29-34. doi: 10.4103/0976-9668.149074.

39. Ohara T, Itaya T, Usami K, Ando Y, Sakurai H, Honda MJ, Ueda M, Kagami H. Evaluation of scaffold materials for tooth tissue engineering. J Biomed Mater Res A 2010;94:800-805. doi: 10.1002/jbm.a.32749.

40. Volponi AA, Pang Y, Sharpe PT. Stem cell-based biological tooth repair and regeneration. Trends Cell Biol 2010; 20:715-722. doi: 10.1016/j.tcb.2010.09.012.

41. Green DW, Lai WF, Jung HS. Evolving marine biomi- 
metics for regenerative dentistry. Mar Drugs 2014;12: 2877-2912. doi: 10.3390/md12052877.

42. Huang X, Bringas P Jr, Slavkin HC, Chai Y. Fate of HERS during tooth root development. Dev Biol 2009; 334:22-30. doi: 10.1016/j.ydbio.2009.06.034.

43. Takahashi C, Yoshida H, Komine A, Nakao K, Tsuji T, Tomooka Y. Newly established cell lines from mouse oral epithelium regenerate teeth when combined with dental mesenchyme. In Vitro Cell Dev Biol Anim 2010;46:457-468. doi: 10.1007/s11626-009-9265-7.

44. Honda MJ, Tsuchiya S, Sumita Y, Sagara H, Ueda M. The sequential seeding of epithelial and mesenchymal cells for tissue-engineered tooth regeneration. Biomaterials 2007;28:680-689. doi: 10.1016/j.biomaterials.2006. 09.039 .

45. Yajima-Himuro S, Oshima M, Yamamoto G, Ogawa M, Furuya M, Tanaka J, Nishii K, Mishima K, Tachikawa T, Tsuji T, Yamamoto M. The junctional epithelium originates from the odontogenic epithelium of an erupted tooth. Sci Rep 2014;4:4867. doi: 10.1038/srep04867.

46. Ohazama A, Modino SA, Miletich I, Sharpe PT. Stemcell-based tissue engineering of murine teeth. J Dent Res 2004;83:518-522. doi: 10.1177/154405910408300702.
47. Ikeda E, Morita R, Nakao K, Ishida K, Nakamura T, Takano-Yamamoto T, Ogawa M, Mizuno M, Kasugai S, Tsuji T. Fully functional bioengineered tooth replacement as an organ replacement therapy. Proc Natl Acad Sci USA 2009;106:13475-13480. doi: 10.1073/pnas. 0902944106.

48. Yamamoto H, Kim EJ, Cho SW, Jung HS. Analysis of tooth formation by reaggregated dental mesenchyme from mouse embryo. J Electron Microsc (Tokyo) 2003; 52:559-566. doi: 10.1093/jmicro/52.6.559.

49. Takahashi K, Yamanaka S. Induction of pluripotent stem cells from mouse embryonic and adult fibroblast cultures by defined factors. Cell 2006;126:663-676. doi: 10.1016/ j.cell.2006.07.024.

50. Cai J, Zhang Y, Liu P, Chen S, Wu X, Sun Y, Li A, Huang K, Luo R, Wang L, Liu Y, Zhou T, Wei S, Pan G, Pei D. Generation of tooth-like structures from integration-free human urine induced pluripotent stem cells. Cell Regen (Lond) 2013;2:6. doi: 10.1186/2045-9769-2-6.

51. Shi L, Cui Y, Luan J, Zhou X, Han J. Urine-derived induced pluripotent stem cells as a modeling tool to study rare human diseases. Intractable Rare Dis Res 2016;5:192-201. doi: 10.5582/irdr.2016.01062. 